\title{
A Study of Variations in Serum Cortisol and Urinary Spot Creatinine Levels in Traumatic Brain Injury Patients
}

\author{
Sivaa $\mathbf{R}^{1}$, Thiagarajan $\mathbf{G}^{2}$, Meenakshi $\mathbf{V}^{3}$, Anil kumar $\mathbf{M}^{4}$ \\ 1, Resident, Department of Biochemistry, Pondicherry Institute of Medical Sciences (PIMS), Pondicherry. \\ 2, Professor and Head, Department of Neurosurgery, Pondicherry Institute of Medical Sciences (PIMS), \\ Pondicherry. \\ 3.Assistant Professor, Department of Biochemistry, Pondicherry Institute of Medical Sciences (PIMS), \\ Pondicherry. \\ 4. Resident, Department of Biochemistry, Pondicherry Institute of Medical Sciences (PIMS), Pondicherry.
}

\begin{abstract}
Traumatic Brain Injury (TBI) due to road traffic accidents is one the leading cause of death in India. Though several radiological diagnostic modalities are available to visualize the extent of injury, no perfect biomarkers are available to access the clinical condition of the patients. Since serum cortisol and urinary creatinine excretion are associated with the patho-physiology of TBI, we aimed to find the association between their levels and the clinical condition of the patients.

Totally 54 TBI patients categorized as mild $(n=23)$, moderate $(n=15)$ and severe $(n=16)$ based on their admission day GCS scores were analyzed for serum cortisol and urinary creatinine at the day of admission and discharge. Both serum cortisol $(<0.0001)$, and urinary spot creatinine $(<0.0001)$ showed a significant difference in their levels between the admission and discharge day. Serum cortisol levels showed a significant correlation among mild and moderate categories. Urinary spot creatinine levels correlated significantly among mild and severe categories. Serum cortisol and urinary spot creatinine are found to be important biomarkers of neurotrauma.
\end{abstract}

Keywords: Traumatic brain injury(TBI), Cortisol, Creatinine.

\section{INTRODUCTION}

Road traffic accidents are one of the growing medical emergencies worldwide and by the end of 2020 it will be the third among the global diseases [1]. In India nearly 2 million people sustain brain injury. Among them 0.2 million people lose their life and nearly a million need rehabilitation every year [2]. Traumatic Brain Injury(TBI) initiates a complex cascade of events, starting with an acute primary injury which triggers the secondary events that evolve over many days, resulting in deleterious patho-physical and biochemical effects [3]. Cortisol is the most abundant circulating steroid and the major glucocorticoid secreted by adrenal cortex [4]. Traumatic brain injury is more frequently associated with the disturbance of hypothalamic-pituitary-adrenal axis secretions [5]. High incidence of major hormonal dysfunction occurs following TBI [6]. Therefore, serum levels of hormones such as cortisol will be altered in response to a brain injury. Any major trauma will lead to a catabolic state [7]. Every day about $20 \mathrm{mg}$ of urinary creatinine per kilogram of body weight is formed from the skeletal muscle by the non enzymatic conversion of phosphocreatine [8]. Hence measurement of urinary creatinine in patients with severe head injury may be used to assess the energy status of the patients.

Even though the diagnosis and the extent of traumatic brain injury can be made out easily by the latest available Radiographic techniques, there is no perfect biomarker available for determining the prognosis of traumatic brain injury in patients. Because of the association of serum cortisol and urinary creatinine in TBI pathophysiology, we did the estimation of their levels at the time of admission and discharge to find whether any correlation existed between their levels and clinical condition of the TBI patients.

\section{MATERIALS AND METHODS}

It was an observational and cross sectional study which included 54 Traumatic brain injury patients (age group 18-60 years) admitted in the Emergency ward of our Hospital during the time period of jan 2012 to june 2013 who underwent non-surgical intervention. Patients with a history of cerebral ischemia, infection and hemorrhage and those patients with Liver failure, Renal failure, Hypertension where excluded from the study. The patients were grouped into 3 categories based on their admission day Glasgow Coma Scale (GCS) score[9], as mild head injury (GCS Score 3 to 8), Moderate (GCS Score 9 to 12) and Severe head Injury (GCS Score 13 to15) category which included 23,15 and 16 TBI patients respectively. 
Blood samples of TBI Patients were collected within 24 hrs of admission and also at the day of their discharge. Serum cortisol levels were estimated by Siemens Immulite 1000 Auto- Analyser under the principle of Solid Phase Competitive Chemiluminescent Enzyme Immunoassay [10].

Estimation of urinary spot Creatinine is done by Jaffe's kinetic method [11], in which creatinine reacts with picric acid in alkaline medium to form an orange coloured complex and the rate of change of its absorbance is measured colorimetrically at $505 \mathrm{~nm}$ at predicted interval of time.

Continuous variables were expressed as mean \pm standard deviation. 'Paired t Test' was used to compare the mean value of the parameters in TBI patients on the day of admission and discharge. Pearson's correlation test ( $\mathrm{r}$ value -1 to +1 ) was used to correlate the levels of parameters with the clinical condition of the patient. A 'p' value of $\leq 0.05$ was accepted as statistically significant.

\section{RESULTS}

The study was done on 54 individuals with varying degree of head injuries. It included 49 males (90.75\%) and 5 females $(9.25 \%)$ with mean age limit of $41 \pm 11$ years.We applied 'Paired $\mathbf{t}$ ' test for all the patients as a whole and as categories on the day of admission and discharge to compare the mean values of serum cortisol and urinary spot creatinine.

Table 1: Comparison of serum cortisol and urinary spot creatinine levels among all head injury patients $(n=54)$ on the day of admission and discharge using 'Paired $t$ test'.

\begin{tabular}{|l|l|l|l|l|}
\hline SI. No & PARAMETERS & DAY OF ADMISSION & DAY OF DISCHARGE & P Value \\
\hline 1 & Serum cortisol $(\mu \mathrm{g} / \mathrm{dl})$ & $30.38 \pm 8.5$ & $24.8 \pm 7.1$ & $<0.0001^{* *}$ \\
\hline 2 & Urinary spot creatinine $(\mathrm{mg} / \mathrm{dl})$ & $56.74 \pm 26$ & $164.1 \pm 41.12$ & $<0.0001^{* *}$ \\
\hline
\end{tabular}

*; <0.05- significant, $\quad * * ;<0.01$-highly significant.

Serum cortisol $(<0.0001)$, and urinary spot creatinine $(<0.0001)$ showed a significant difference in their levels (Table 1).

Table 2: Comparison of serum cortisol and urinary spot creatinine levels on the day of admission and discharge among different categories of patients with traumatic brain injury.

\begin{tabular}{|c|c|c|c|c|c|c|c|c|c|}
\hline \multirow[t]{3}{*}{ Parameters } & \multicolumn{9}{|c|}{ Category of patients } \\
\hline & \multicolumn{3}{|c|}{ Cat-I } & \multicolumn{3}{|c|}{ Cat-II } & \multicolumn{3}{|l|}{ Cat-III } \\
\hline & $\mathbf{A}$ & D & $\mathbf{P}$ & $\mathbf{A}$ & D & $\mathbf{P}$ & $\mathbf{A}$ & D & $\mathbf{P}$ \\
\hline $\operatorname{Cortisol}(\mu \mathrm{g} / \mathrm{dl})$ & $\begin{array}{l}29.69 \\
\pm 9.46\end{array}$ & $\begin{array}{l}23.63 \\
\pm 8.3\end{array}$ & $<0.001^{* * *}$ & $\begin{array}{l}27.72 \\
\pm 8.31\end{array}$ & $\begin{array}{l}23.03 \\
\pm 6.86\end{array}$ & $0.02^{*}$ & $\begin{array}{l}32.08 \\
\pm 8.44\end{array}$ & $\begin{array}{l}26.04 \\
\pm 6.52\end{array}$ & $<0.001^{* * *}$ \\
\hline $\begin{array}{l}\text { Urinary spot } \\
\text { Creatinine } \\
\text { (mg/dl ) }\end{array}$ & $\begin{array}{l}71.81 \\
\pm 31\end{array}$ & $\begin{array}{l}180.15 \\
\pm 14.88\end{array}$ & $<0.001^{* * *}$ & $\begin{array}{l}51.07 \\
\pm 25.3\end{array}$ & $\begin{array}{l}162.47 \\
\pm 44.12\end{array}$ & $<0.001 * *$ & $\begin{array}{l}44.06 \\
\pm 11.99\end{array}$ & $\begin{array}{r}109.78 \\
\pm 56.19\end{array}$ & $<0.001^{\text {*** }}$ \\
\hline
\end{tabular}

Day of admission (A), Day of discharge (D), *; <0.05- significant, **; <0.01-highly significant.

All three groups of head injury patients (category I to III), showed a significant difference in serum cortisol and urinary spot creatinine levels between the day of admission and discharge (Table 2).

Table 3: Correlation between changes in Glasgow Coma Scale score with cortisol and urinary spot creatinine level changes in different category of patients with traumatic brain injury.

\begin{tabular}{|c|c|c|c|c|c|}
\hline \multirow[t]{2}{*}{ Change in parameters } & \multirow{2}{*}{$\begin{array}{l}\text { Category of } \\
\text { patients }\end{array}$} & \multicolumn{2}{|c|}{ Admission } & \multicolumn{2}{|c|}{ Discharge } \\
\hline & & $\mathbf{r}$ & $\mathbf{P}$ & $\mathbf{r}$ & $\mathbf{P}$ \\
\hline \multirow[t]{3}{*}{ Serum cortisol } & \multirow{3}{*}{$\begin{array}{l}\text { I } \\
\text { II } \\
\text { III }\end{array}$} & -0.30 & $>0.1$ & -0.51 & $<0.05^{*}$ \\
\hline & & 0.62 & $<0.05^{*}$ & 0.64 & $<0.01^{3 * 9}$ \\
\hline & & -0.06 & $>0.1$ & -0.08 & $>0.1$ \\
\hline \multirow[t]{3}{*}{ Urine spot creatinine } & \multirow{3}{*}{$\begin{array}{l}\text { I } \\
\text { II } \\
\text { III }\end{array}$} & 0.26 & $>0.1$ & 0.66 & $<0.001^{*}$ \\
\hline & & -0.44 & $>0.05$ & -0.01 & $>0.1$ \\
\hline & & -0.29 & $>0.1$ & 0.56 & $<0.05^{*}$ \\
\hline
\end{tabular}

*; <0.05- significant, $\quad * * ;<0.01$-highly significant. 
Pearson's correlation test was applied for correlating the changes in their GCS score with the changes in the levels of biochemical parameters. We found that there was a significant correlation between the GCS scores changes and the changes in the level biochemical parameters done at the time of admission and discharge (Table $3)$.

\section{DISCUSSION}

Neuro-endocrine dysfunction is highly prevalent in patients admitted with moderate and severe TBI [12]. The acceleration and deceleration forces causing injury to the white matter particularly that of the medial temporal lobes, diencephalon and brain stem leading to results in hormonal abnormalities [13]. These things may be aggravated by vascular insults like hypoxia, ischemia and edema [14].According to Woolf PD et al [15], the response of pituitary gland to acute trauma and the resulting hormonal changes in the circulation become apparent during the first hours and days and it may continue throughout the period of acute illness.

As a result of the physiological response to head injury, there occurs an increase in the levels of hormones like cortisol, glucagon and epinephrine, leading to gluconeogenesis and stress hyperglycemia [16]. Cytokine activation and corticotrophin release during the initial acute stage of trauma is also associated with high serum cortisol levels [17]. In the present study, we found significantly higher $(\mathrm{P}=<0.001)$ admission day cortisol levels than that of the discharge day signifying the body's response to a sudden stress.

A significant negative correlation existed between the change in GCS score with that of the change in the cortisol levels in grade I and II head injury patients; but not with those with severe head injury (Table 3). Our results are in strong aggrement with the study done by Barton et al [18].The non-correlation seen in the severe head injury patients may be explained by the excessive damage caused to the hypothalamus and/or the pituitary by greater shear forces, thus resulting in blunted response [19].

Stress due to any trauma will induce a catabolic state [20]. This catabolic state causes the release of amino acids which gets oxidized to yield urea as the main end product along with other non proteinaceous nitrogen substances like creatinine [21]. A very high significant difference was observed in the urinary spot creatinine levels $(\mathrm{P}<0.001)$ between the admission day and discharge day in all the categories of head injury patients. To the best of our knowledge this was the first study to measure the urinary spot creatinine in TBI patients. A previous study [3], measured 24-hours urinary creatinine in patients with TBI and concluded that, severe TBI is associated with reduced creatinine excretion.

Urinary creatinine excretion is a reliable marker for accessing the nutritional status of the head injury patients [7]. In our study, the admission day values were found to be very low when compared to the discharge day. Following head injury, stress sensors like cortisol and norepinephrine tend to rise which stimulates gluconeogenesis. This might lead to reduced bioavailability of free amino acids for protein synthesis such as creatine in the skeletal muscle. This may explain the reduced urinary excretion of creatinine in patients of TBI as was seen in present study. Besides these, nutritional deprivation in emergency setting; especially following admission, leads to an energy deprived state which also explains the reduced urinary creatinine excretion. As patients are subsequently put on parenteral nutrition (based on the severity), the urinary levels tend to rise. Almost all the patients in the present study showed normal urinary spot creatinine during discharge as most of them were on normal adequate diet by that time.

\section{CONCLUSION}

In our study we found that the serum cortisol and urinary spot creatinine levels are well correlating with the changes in the clinical condition of the TBI patients implicating their role in the pathophysiology following neurotrauma. Further large prospective studies involving different inflammatory and biochemical parameters should be carried out in order to establish their role as a biomarker in TBI patients for diagnostic, prognostic and therapeutic indications. 


\section{REFERENCES:}

[1.] Lopez AD, Murray CC. The global burden of disease 1990-2020. Nature Medicine 1998;4:12411243.

[2.] Gururaj G. Epidemiology of Traumatic Brain Injuries: Indian Scenario. Neurological Research 2002;24:1-5.

[3.] Dhandapani SS, Manju D, Vivekanandhan S, Agarwal M, Mahapatra AK. Prospective longitudinal study of biochemical changes in critically ill patients with severe traumatic brain injury: Factors associated and outcome at 6 month. Indian Journal of Neurotrauma 2010;7(1):2328

[4.] Kaplan LA, Pesce AJ. Clinical Chemistry. $5^{\text {th }}$ edition. Missouri. Mosby:Elsevier;2010. Chapter 51. Adrenal Hormones And Hypertension; P.1001.

[5.] Llompart-Pou JA, Perez G, Riesco M, Perez-Barcena J, Brell M, Ibanez J. Loss of cortisol circadian rhythm in patients with traumatic brain injury: A microdialysis Evaluation. Neurocrit care 2010;13(2):211-6

[6.] Krahulik D, Zapletalova J, Frysak Z, Vaverka M. Dysfunction of hypothalamic-hypophysial axis after traumatic brain injury in adults. J Neurosurg 2010;113:581-584

[7.] Carlotti APCP, Bohn D, Matsuno AK, Pasti DM, Gowrishankar M, Halperin ML. Indicators of lean body mass catabolism: emphasis on the creatinine excretion rate. Q J Med 2008;101:197-205.

[8.] Walser M. Creatinine as a measure as a of protein nutrition in adults of varying age. J Parenter Enteral Nutr 1997;11:573-578.

[9.] Teasdale G, Jennett B. Assessment of coma and impaired consciousness. Lancet

[10.] 974;2:81- 84 .

[11.] Ruder H. A radio immunoassay for cortisol in plasma and urine. J clin Endo Metab 1972; 35:219

[12.] Burtis CA, Ashwood ER, Bruns DE. Teitz text book of clinical chemistry and molecular diagnosis. $4^{\text {th }}$ edition. New Delhi:Elsevier Saunders;2006. Chapter 24, Kidney Function Tests; p.798.

[13.] Kelly DF, Gonzalo IT, Cohan P et al. Hypopituitarism following traumatic brain injury and aneurysmal subarachnoid hemorrhage: a preliminary report. J Neurosurg 2000;93:743-752.

[14.] Gaetz M. The neurophysiology of brain injury. Clin Neurophysiol 2004;115:4-18.

[15.] Casanueva FF, Ghigo E, Popovic V. Hypopituitarism following traumatic brain injury:a guideline Decalogue. J Endocrinol Invest 2004;27:793-795.

[16.] Woolf PD, Hamill RW, McDonald JV et al. Transient hypogonadotropic hypogonadism caused by critical illness. J Clin Endocrinol Metab 1985;60:444-450.

[17.] Rovlias A, Kotsou S. The influence of hyperglycemia on neurological outcome in patients with severe head injury. Neurosurgery 2000;46:335-342.

[18.] Feibel J, Kelly M, Lee L, Woolf P. Loss of adrenocortical suppression after acute brain injury: role of increased intracranial pressure and brain stem function. J Clin Endocrinol Metab 1983;57:1245-1250.

[19.] Barton RN, Stoner HB, Watson. Relationships among plasma cortisol, adrenocorticotrophin and severity of injury in recently injured patients. J trauma 1987;27:384-392.

[20.] Tanriverdi F, Senyurek H, Unluhizarci K, Selcuklu A, Casanueva FF, Kelestimur F. High risk of hypopituitarism after traumatic brain injury: a prospective investigation of anterior pituitary function in the acute phase and 12 months after trauma. The Journal of Clinical Endocrinology \& Metabolism 2006;91(6):2105-2111.

[21.] Shew SB, Jaksic T. The metabolic needs of critically ill children and neonates. Semin pediatr surg 1999;8:131-139.

[22.] Altman PL, Ditter DS. Blood and other body fluids. The Biology Data Book. $18^{\text {th }}$ ed. Washington DC: Federation of American Societies for Experimental Biology;1992:1990-1992. 